\title{
Peak flow variation in childhood asthma: correlation with symptoms, airways obstruction, and hyperresponsiveness during long term treatment with inhaled corticosteroids
}

Paul L P Brand, Eric J Duiverman, Herman J Waalkens, Elisabeth E M van Essen-Zandvliet, Karel F Kerrebijn, and the Dutch CNSLD Study Group

\begin{abstract}
Background-Guidelines for asthma management focus on treatment with inhaled corticosteroids and on home recording of peak expiratory flow (PEF). The effect of maintenance treatment with inhaled corticosteroids on PEF variation and its relation to other parameters of disease activity were examined in 102 asthmatic children aged 7-14 years.

Methods-During 20 months of treatment with inhaled salbutamol, with or without inhaled budesonide ( $600 \mu \mathrm{g}$ daily), forced expiratory volume in one second $\left(F E V_{1}\right)$, the dose of histamine required to provoke a fall in $\mathrm{FEV}_{1}$ of more than $20 \%\left(\mathrm{PD}_{20}\right)$, the percentage of symptom free days, and PEF variation were assessed bimonthly. PEF variation was computed as the lowest $P E F$ as a percentage of the highest PEF occurring over 14 days, the usual way of expressing PEF variation in asthma selfmanagement plans. For each patient using inhaled corticosteroids within subject correlation coefficients $(\rho)$ were computed of PEF variation to the percentage of symptom free days, $F_{E V}$, and $P_{20}$.

Results-PEF variation decreased significantly during the first two months of treatment with inhaled corticosteroids and then remained stable. The same pattern was observed for symptoms and $\mathrm{FEV}_{1}$. In contrast, $\mathbf{P D}_{20}$ histamine continued to improve throughout the whole follow up period. In individual patients predominantly positive associations of PEF variation with symptoms, $F_{E V}$, and $\mathbf{P D}_{20}$ were found, but the ranges of these associations were wide.

Conclusions-During treatment with inhaled corticosteroids the changes in PEF variation over time show poor concordance with changes in other parameters of asthma severity. When only PEF is monitored, clinically relevant deteriorations in symptoms, $\mathrm{FEV}_{1}$, or $\mathrm{PD}_{20}$ may be missed. This suggests that home recording of PEF alone may not be sufficient to monitor asthma severity reliably in children.

(Thorax 1999;54:103-107)
\end{abstract}

Keywords: asthma; children; inhaled corticosteroids; peak expiratory flow; home monitoring
Current guidelines for management of childhood asthma focus on two principles: maintenance treatment with anti-inflammatory drugs (most commonly inhaled corticosteroids) and home recording of symptoms and peak expiratory flow (PEF). ${ }^{12}$ The effectiveness of inhaled corticosteroids for childhood asthma has been well established. ${ }^{3} \quad$ Self-management programmes for childhood asthma, comprising both patient education and PEF based adaptation of the dosage of corticosteroids, are effective in reducing asthma morbidity in children. ${ }^{4}$ It is unknown, however, whether it is the education or the PEF monitoring that is responsible for this success. In fact, a study in adult asthmatic patients has shown that a PEF based self-management programme is no more effective than a programme based on education alone. ${ }^{6}$ Another study in adults showed that a symptom based self-management programme was just as effective as a PEF based programme. ${ }^{7}$ Similarly, it has been shown that education alone can reduce the exacerbation rate in childhood asthma. ${ }^{8}$ Despite the lack of knowledge on the usefulness of home monitoring of PEF, it has become very popular in contemporary asthma management. The Global Initiative for Asthma (GINA) guidelines recommend that every patient with asthma should have his own portable PEF meter and state that long term home recordings of PEF are desirable. ${ }^{2}$ In clinical practice this often means that asthmatic children of school age monitor their asthma and its response to treatment primarily based on home PEF recordings. ${ }^{9}$ Indeed, the degree of variation of $\mathrm{PEF}$ is considered to be the golden standard for assessing the severity of childhood asthma and monitoring in some studies. ${ }^{10}{ }^{11}$

Surprisingly few studies have examined changes in PEF over longer periods of time in asthmatic children. Most of these studies have been population based ${ }^{12-15}$ and the subjects in these studies received little, if any, treatment for asthma. To date no studies have been published on changes in PEF over time in asthmatic children receiving treatment with inhaled corticosteroids. We therefore analysed changes in home recorded PEF in asthmatic children during long term maintenance therapy with inhaled corticosteroids. The aim of the study was to assess the pattern of PEF variation over time and its relationship to changes in other parameters of disease activity.
4 November 1998

Accepted for publication

5 November 1998 




Figure 1 Changes in PEF variation (expressed as the lowest PEF level obtained in each follow up period as a percentage of the highest PEF level occurring in that period, low\%high) during treatment with inhaled $\beta_{2}$ agonists alone (closed circles) or in combination with inhaled corticosteroids (open squares). Data points represent mean values; bars represent standard errors. meter was brought along for inspection and each patient was asked to demonstrate a satisfactory PEF manoeuvre.

Diary cards with missing values for more than two of the 14 days were excluded from the analysis. For each diary card the percentage of symptom free days was calculated. Based on our earlier study, ${ }^{17} \mathrm{PEF}$ variation was expressed as low\%high (the lowest PEF value occurring over each 14 day period expressed as a percentage of the highest PEF occurring during that time period). This index was chosen rather than the commonly used amplitude\%mean (highest PEF on each day minus the lowest PEF on that day, expressed as a $\%$ of their mean, averaged over 14 days), firstly because low\%high is the expression commonly used in asthma self-management plans ${ }^{5}$ and, secondly, because it has been shown to be more effective than amplitude $\%$ mean in identifying short episodes of reduced PEF. ${ }^{17} 19$

The relation of PEF variation to other indices of disease activity was examined in two ways. Changes in PEF variation (low\%high) over time were compared with changes in symptoms and $\mathrm{PD}_{20}$ in the group treated with inhaled corticosteroids. In addition, for each patient in the BA+ICS group a within subject Spearman correlation coefficient was calculated between $\mathrm{PEF}$ variation and the \% of symptom free days, $\mathrm{FEV}_{1} \%$ pred, and $\mathrm{PD}_{20}$. These analyses were confined to the BA+ICS group because this group received treatment that is now considered to be the standard care for asthmatic children. The treatment applied to the other group (maintenance treatment with inhaled bronchodilators) is no longer advocated, and the relationship between different indices of disease activity in this study group was considered to be less relevant. fter withdrawal of anti-inflammatory maintenance therapy, and age 7-14 years. Informed consent was received from all subjects and the study was approved by the hospital ethics review boards of all participating centres.

Before entering the trial all maintenance therapy for asthma was withdrawn and patients used inhaled $\beta_{2}$ agonists on demand only for two weeks. Subsequently they were randomised to treatment, consisting of inhaled $\beta_{2}$ agonists (salbutamol $200 \mu \mathrm{g}$ ) plus inhaled corticosteroid (budesonide $200 \mu \mathrm{g}$ ) (BA+ICS), or inhaled $\beta_{2}$ agonists plus placebo (BA+PL), by metered dose inhaler three times daily administered in a double blind fashion. Rescue medication consisted of inhaled fenoterol dry powder. $^{16}$

Patients returned to the clinic every two months. At each follow up visit the $\mathrm{FEV}_{1}$ was measured; $\mathrm{PD}_{20}$ histamine was assessed at alternate visits. $\mathrm{FEV}_{1}$ was expressed as a percentage of the reference (or predicted) value $\left(\mathrm{FEV}_{1} \%\right.$ pred). ${ }^{18} \mathrm{PD}_{20}$ values were log transformed before analysis.

Before each visit patients recorded symptom scores and PEF values (twice daily before inhaling trial medication) in a diary for 14 days. At the start of the study each patient received a new mini-Wright PEF meter (Clement Clarke, Harlow, UK) and standardised instructions on how to use it. At each follow up visit the PEF

\section{WITHDRAWALS AND THEIR INFLUENCE ON RESULTS}

The length of follow up from randomisation to termination of the study ranged from 10 to 28 (median 22) months. The study was terminated because about $40 \%$ of the patients in the $\mathrm{BA}+\mathrm{PL}$ arm had to be withdrawn from the study due to worsening of their asthma. ${ }^{16}$ Because of this selective withdrawal and variable follow up, the number of diary cards available for analysis decreased rapidly after 20 months of follow up. The results are therefore confined to the first 20 months of blinded follow up. Children who were withdrawn from the study had lower levels of PEF, $\mathrm{FEV}_{1}$, and $\mathrm{PD}_{20}$ than children who remained in the study. As a result, mean levels of these indices in the $\mathrm{BA}+\mathrm{PL}$ group are inflated due to selective withdrawal of those with lower levels. ${ }^{16}$

\section{PEF CORRECTIONS}

PEF can be corrected for height although, even after such a correction, considerable variation in PEF between subjects remains. ${ }^{20}$ This is one of the reasons why PEF is usually not expressed as a percentage of a height corrected reference stead, each PEF level is expressed as a percentage of the patient's best value. For the purpose value in asthma self-management plans. In- 


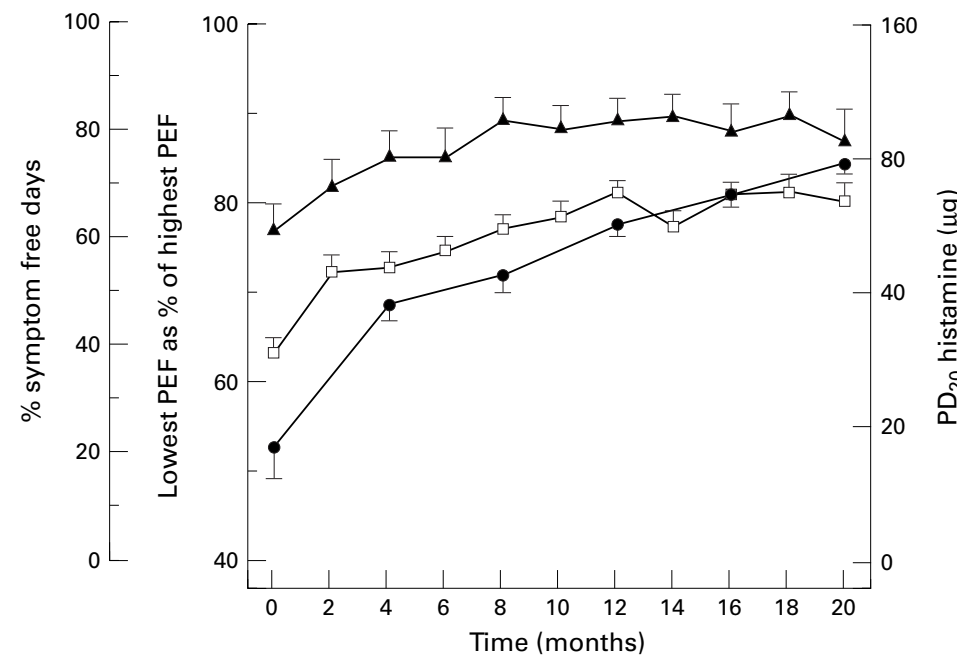

Figure 2 Changes in PEF variation (expressed as the lowest PEF level obtained in each follow up period as a percentage of the highest PEF level occurring in that period; open squares), percentage of symptom free days (triangles), and $P D_{20}$ histamine (solid circles) in 44 children during long term treatment with inhaled $\beta_{2}$ agonists and corticosteroids. Data points represent mean values; bars represent standard errors.

Table 1 Mean (SD) or number (\%)* baseline characteristics of 44 children who completed 20 months of follow up on maintenance therapy with inhaled $\beta_{2}$ agonists and inhaled corticosteroids

\begin{tabular}{|c|c|}
\hline Male gender $\star$ & $32(73 \%)$ \\
\hline Inhaled steroids before study ${ }^{\star}$ & $21(48 \%)$ \\
\hline Smoking in household ${ }^{\star}$ & $25(57 \%)$ \\
\hline Age (years) & $11.1(1.8)$ \\
\hline Duration of asthma (years) & $7.5(3.3)$ \\
\hline $\log _{2} \mathrm{PD}_{20}$ histamine $(\mathrm{mg})$ & $4.3(1.4)$ \\
\hline Geometric mean & 19.3 \\
\hline $\mathrm{FEV}_{1} \%$ predicted & $77.3(10.9)$ \\
\hline Morning PEF (1/min) & $289(73)$ \\
\hline Amplitude $\%$ mean (\%) & $13.6(6.5)$ \\
\hline Low \% high PEF (\%) & $63.5(11.5)$ \\
\hline $\log _{10}$ eosinophil count $\left({ }^{\star} 10^{6} / 1\right)$ & $2.5(0.4)$ \\
\hline Geometric mean & 315 \\
\hline $\log _{10}$ total serum IgE (IU/1) & $2.7(0.4)$ \\
\hline Geometric mean & 490 \\
\hline
\end{tabular}

of this paper analyses with PEF were performed, both with and without height correction. Similarly, analyses of PEF were performed with and without correction for the inaccuracy of the PEF meter. ${ }^{21} 22$

Statistical analyses were performed using SPSS for Windows, version 8.0.

\section{Results}

Of 116 children who were randomised to receive blinded medication, ${ }^{16} 102$ (75 boys) filled out their baseline diary card completely. ${ }^{17}$ Their mean (SD) age was 11 (2) years and mean $\mathrm{FEV}_{1}$ was 79 (12)\% predicted. The geometric mean $\mathrm{PD}_{20}$ was $18.4 \mu \mathrm{g}$. Mean morning PEF was $281(68) 1 / \mathrm{min}$, and mean afternoon PEF was 305 (76) $1 / \mathrm{min}$. The mean lowest PEF over the 14 day baseline period was $63(16) \%$ of the highest PEF during this period. Mean diurnal PEF variation (amplitude $\%$ mean) was $13.7(8.1) \%$. The two treatment groups were comparable with respect to all baseline characteristics. ${ }^{16}$

$\mathrm{PEF}$ improved during the first two months in children on BA+ICS while remaining unchanged in the BA+PL group (95\% CI for difference after two months 17 to $77 \mathrm{l} / \mathrm{min}$ for morning PEF and 10 to $71 \mathrm{l} / \mathrm{min}$ for afternoon $\mathrm{PEF})$. This difference did not change during

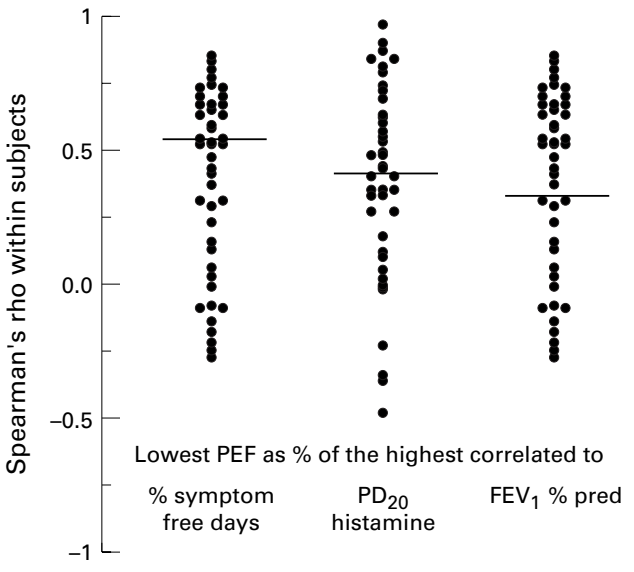

Figure 3 Within subject Spearman correlation coefficients of PEF variation (expressed as the lowest PEF level obtained in each follow up period as a percentage of the highest PEF level occurring in that period, low\%high) to the percentage of symptom free days, $P D_{20}$ histamine, and $F E V_{1} \%$ predicted in 44 children during long term treatment with inhaled $\beta_{2}$ agonists and corticosteroids. Points represent individual values for Spearman's $\rho$; bars represent median values.

further follow up. In both groups PEF slowly improved throughout further follow up, which is attributable to increase in height. ${ }^{16}$ Correcting PEF values for these changes in height during the study did not alter the results of the analyses.

The changes in PEF variation over time in both treatment groups are depicted in fig 1 . Low\%high increased during the first two months of treatment with inhaled corticosteroids (95\% CI for difference 6.6 to $20.5 \%$ ) and then remained stable $(95 \%$ CI for difference after 20 months of follow up 6.2 to $19.0 \%$ ). Amplitude\%mean followed a similar pattern of improvement. The small increases in PEF variation seen after the second month could be due in part to withdrawal of unstable patients with high PEF variation.

In fig 2 changes in three different indices of disease activity during maintenance treatment with inhaled corticosteroids are plotted. Whereas improvements in the percentage of symptom free days and PEF variation (low\%high) levelled off after the first year of treatment, $\mathrm{PD}_{20}$ histamine continued to improve throughout the whole follow up period.

Forty four children in the BA+ICS group completed 20 months of follow up (table 1). For each of these children within subject Spearman correlation coefficients between low\%high PEF, the percentage of symptom free days, $\mathrm{PD}_{20}$ histamine, and $\mathrm{FEV}_{1} \%$ predicted were computed (fig 3, table 2). Predominantly positive associations were found and mean Spearman's $\rho$ values were significantly different from 0 (95\% CI for mean $\rho$ of low\%high PEF to percentage symptom free days was 0.28 to 0.49 , to $\mathrm{PD}_{20}$ it was 0.27 to 0.49 , and to $\mathrm{FEV}_{1} \%$ predicted it was 0.19 to 0.37). However, the ranges were wide and, in a considerable number of patients, the correlation coefficients were negative (fig 3 ). The results of these analyses remained the same when another index of PEF variation (amplitude\%mean) was used, and when PEF 
Table 2 Median within individual Spearman correlation coefficients between various parameters of disease activity in 44 asthmatic children during long term (20 months) treatment with inhaled corticosteroids

\begin{tabular}{|c|c|c|c|c|c|}
\hline & $\begin{array}{l}\text { Lowest PEF as \% of } \\
\text { highest (low\%high) }\end{array}$ & Amplitude \% mean & $\begin{array}{l}\% \text { of symptom free } \\
\text { days }\end{array}$ & $F E V_{1}$ & $P D_{20}$ \\
\hline Lowest PEF as \% of highest (low\%high) & & $-0.80(-0.95,-0.38)$ & $0.52(-0.27,0.85)$ & $0.33(-0.50,0.76)$ & $0.40(-0.48,0.97)$ \\
\hline Amplitude $\%$ mean & $-0.80(-0.95,-0.38)$ & & $-0.39(-0.88,0.52)$ & $-0.27(-0.90,0.54)$ & $-0.44(-0.91,0.55)$ \\
\hline$\%$ of symptom free days & $0.52(-0.27,0.85)$ & $-0.39(-0.88,0.52)$ & & $0.23(-0.59,0.84)$ & $0.27(-0.70,0.80)$ \\
\hline $\mathrm{FEV}_{1}$ & $0.33(-0.50,0.76)$ & $-0.27(-0.90,0.54)$ & $0.23(-0.59,0.84)$ & & $0.21(-0.70,0.93)$ \\
\hline $\mathrm{PD}_{20}$ & $0.40(-0.48,0.97)$ & $-0.44(-0.91,0.55)$ & $0.27(-0.70,0.80)$ & $0.21(-0.70,0.93)$ & \\
\hline
\end{tabular}

For each correlation the range (minimum, maximum) of Spearman's rank correlation coefficients is given.

values were corrected for the inaccuracy of the mini-Wright PEF meter.

\section{Discussion}

This study shows that maintenance therapy with inhaled corticosteroids in asthmatic children reduces PEF variation considerably. At first sight this result does not seem to be very surprising because the efficacy of inhaled steroids in childhood asthma is well established. ${ }^{316}$ Most studies on inhaled corticosteroids, however, have only assessed the effects on PEF levels, not PEF variation. This is curious because PEF variation is considered by many to be the golden standard of asthma severity. ${ }^{2}{ }^{10}{ }^{11}$ In only four studies have the effects of inhaled corticosteroids on PEF variation been reported. In mild or episodic asthma inhaled corticosteroids do not reduce PEF variation, probably because it was not very high at the start of the study. ${ }^{23}{ }^{24}$ In moderately severe childhood asthma long term treatment with inhaled corticosteroids has been shown to reduce PEF variation. ${ }^{16}{ }^{25} \mathrm{In}$ each of these studies PEF variation was expressed as amplitude \%mean. There is now accumulating evidence that this way of expressing PEF variation, apart from being very cumbersome to calculate, will fail to identify short lasting episodes of reduced $\mathrm{PEF}^{2627}$ or clinically relevant symptomatic exacerbations. ${ }^{17}{ }^{19}$ Such episodes are probably better appreciated by expressing PEF variation as the lowest level occurring over a given time period as a percentage of the highest level obtained over that time period. This expression has the additional advantages that it is very easy to calculate and corresponds with PEF indices used in selfmanagement plans. ${ }^{17}$

We therefore chose to express PEF variation as the lowest value as a percentage of the highest value over a given period of time (low\%high). In the analyses presented in this paper the use of amplitude\%mean instead of low\%high as an expression of PEF variation did not alter the results.

The most important finding of this study is that, during maintenance treatment with inhaled corticosteroids, changes in PEF variation correspond quite variably with other indices of disease activity. At group level improvements in symptom scores and PEF variation levelled off after 12 months of treatment whereas airways hyperresponsiveness to histamine continued to improve throughout the entire 20 month follow up period (fig 2). More importantly, a considerable number of individual patients showed improvements in symptom free days, $\mathrm{FEV}_{1}$, or $\mathrm{PD}_{20}$ histamine whilst their PEF variation worsened (fig 3, table 2). This observation is in accordance with earlier studies showing poor concordance of changes in PEF levels over time to changes in symptoms, ${ }^{28} \mathrm{FEV}_{1}{ }^{29}$ or methacholine responsiveness. ${ }^{28}$ These results show that, when only PEF values and their changes over time are recorded in asthmatic children, clinically relevant deteriorations in symptoms, airway calibre, and airways hyperresponsiveness may be missed. Clearly this is undesirable in the management of asthma in children.

Thus, the current emphasis on home recording of PEF may not be justified. At present there is no simple way of assessing the degree of airways inflammation in childhood asthma. As long as it is unknown which parameter provides the best or most important information on the severity and the course of childhood asthma, it appears prudent to have asthmatic children return to the clinic regularly to review their symptoms and to perform spirometric and/or other lung function tests, such as those aimed at assessing airways hyperresponsiveness. If PEF is recorded at home the values must be interpreted in the light of the clinical situation as well as using other parameters of disease activity.

The variable relation of changes in PEF to other indicators of disease activity may also explain why researchers have so far been unable to demonstrate the additional benefit of recording home PEF over and above recording symptom scores alone as a basis for adjusting therapy in asthma self-management plans. ${ }^{6730}$ Currently available evidence suggests that the most important part of asthma selfmanagement in children is to educate them to respond promptly to symptoms which suggest an impending exacerbation. ${ }^{48}$

In summary, this study shows that changes in PEF variation during long term treatment with inhaled corticosteroids in childhood asthma correlate quite variably to changes in symptoms, degree of airways obstruction, and histamine hyperresponsiveness. This indicates that recording changes in PEF level alone is insufficient to monitor asthma severity reliably in children. Home PEF records can be useful for assessing and monitoring asthma in children but should not be regarded as the golden standard.

This study was funded by a grant from the Netherlands' Government Health Research Promotion Programme (SGO). Study drugs were supplied by Glaxo Wellcome, Astra, and Boehringer Ingelheim.

1 British Thoracic Society, National Asthma Campaign, Royal College of Physicians of London, et al. The British guidelines on asthma management: 1995 review and position statement. Thorax 1997;52(Suppl 1):S1-S21 2 National Heart Lung and Blood Institute, National 
diagnosis and treatment of asthma (NHLBI Publication

3 Calpin C, Macarthur C, Stephens D, et al. Effectiveness of prophylactic inhaled steroids in childhood asthma: a systematic review of the literature. 7 Allergy Clin Immunol 1997;100:452-7.

4 Madge P, McColl J, Paton J. Impact of a nurse-led home management training programme in children admitted to hospital with acute asthma: a randomised controlled study. Thorax 1997;52:223-8.

5 Charlton I, Antoniou AG, Atkinson J, et al. Asthma at the interface: bridging the gap between general practice and a district general hospital. Arch Dis Child 1994;70:313-8.

6 Grampian Asthma Study of Integrated Care (GRASSIC). Effectiveness of routine self monitoring of peak flow in patients with asthma. BMF 1994;308:564-7.

7 Turner MO, Taylor D, Bennett R, et al. A randomized trial comparing peak expiratory flow and symptom selfmanagement plans for patients with asthma attending a primary care clinic. Am f Respir Crit Care Med 1998;157: 540-6.

8 Ronchetti R, Indinnimeo L, Bonci E, et al. Asthma self-management programmes in a population of Italian schoolchildren: a multicentric study. Eur Respir 7 1997;10 1248-53.

9 Brewis RAL. Patient education, self management plans and peak flow measurement. Respir Med 1991;85:457-62.

10 Linna O. Spirometry, bronchodilator test or symptom scoring for the assessment of childhood asthma. Acta Paediat 1996;85:554-9.

11 Sly PD. Relationship between change in PEF and symptoms: questions to ask in paediatric clinics. Eur Respir f 1997;10 (Suppl 24):80-3s.

12 Clough JB, Williams JD, Holgate ST. Effect of atopy on the natural history of symptoms, peak expiratory flow, and bronchial responsiveness in 7- and 8-year- old children with cough and wheeze. Am Rev Respir Dis 1991;143:75560.

13 Clough JB, Holgate ST. Episodes of respiratory morbidity in children with cough and wheeze. Am $\mathcal{F}$ Respir Crit Care Med 1994:150:48-53.

14 Clough JB, Sly PD. Association between lower respiratory tract symptoms and falls in peak expiratory flow in children. Eur Respir f 1995;8:718-22.

15 Frischer T, Meinert R, Urbanek R, et al. Variability of peak expiratory flow rate in children: short and long term reproducibility. Thorax 1995;50:35-9.

16 van Essen-Zandvliet EEM, Hughes MD, Waalkens HJ, et al. Effects of 22 months of treatment with inhaled corticosteroids and/or $\beta_{2}$-agonists on lung function, airway
responsiveness, and symptoms in children with asthma. $\mathrm{Am}$ Rev Respir Dis 1992;146:547-54.
17 Brand PLP, Duiverman EJ, Postma DS, et al and the Dutch CNSLD Study Group. Peak flow variation in childhood asthma: relationship to symptoms, atopy, airways obstruction and hyperresponsiveness. Eur Respir F 1997;10:12427.

8 Zapletal A, Samanek M, Paul T. Lung function in children and adolescents. Methods, reference values. In: Zapletal A, ed. Progress in respiration research 1987;22:114-218.

19 Toogood JH, Andreou P, Baskerville J. A methodological assessment of diurnal variability of peak flow as a basis for comparing different inhaled steroid formulations. F Allergy Clin Immunol 1996;98:555-62.

20 Taylor MRH. Asthma: audit of peak flow rate guidelines for admission and discharge. Arch Dis Child 1994;70:432-4.

21 Miller MR, Dickinson SA, Hitchings DJ. The accuracy of portable peak flow meters. Thorax 1992;47:904-9.

22 Brand PLP, Waalkens HJ, Duiverman EJ, et al and the Dutch CNSLD Study Group. Inaccuracy of portable peak flow meters: correction is not needed. Acta Paediatr 1997;86:888-9.

23 Waalkens HJ, Gerritsen J, Koëter GH, et al. Budesonide and terbutaline or terbutaline alone in children with mild asthma: effects on bronchial hyperresponsiveness and diurnal variation in peak flow. Thorax 1991;46:499-503.

24 Doull IJM, Lampe FC, Smith S, et al. Effect of inhaled corticosteroids on episodes of wheezing associated with viral infection in school age children: randomised double blind placebo controlled trial. BMF 1997;315:858-62.

25 Simons FER, Canadian Beclomethasone DipropionateSalmeterol Xinafoate Study Group. A comparison of beclomethasone, salmeterol, and placebo in children with asthma. N Engl F Med 1997;337:1659-65.

26 Siersted HC, Hansen HS, Hansen N-CG, et al. Evaluation of peak expiratory flow variability in an adolescent population sample: the Odense schoolchild study. Am f Respir Crit Care Med 1994;149:598-603.

27 Reddel HK, Salome CM, Peat JK, et al. Which index of peak expiratory flow is most useful in the management of stable asthma? Am F Respir Crit Care Med 1995;151:1320-5.

28 Gern JE, Eggleston PA, Schuberth KC, et al. Peak flow variation in childhood asthma: a three-year analysis. F Allergy Clin Immunol 1994;93:706-16.

29 Sly PD, Cahhill P, Willet K, et al. Accuracy of mini peak flow meters in indicating changes in lung function in children with asthma. BMF 1994;308:572-4.

30 Uwyyed K, Springer C, Avital A, et al. Home recording of PEF in young asthmatics: does it contribute to management? Thorax 1996;8:872-9. 